\title{
Meeting the Editors
}
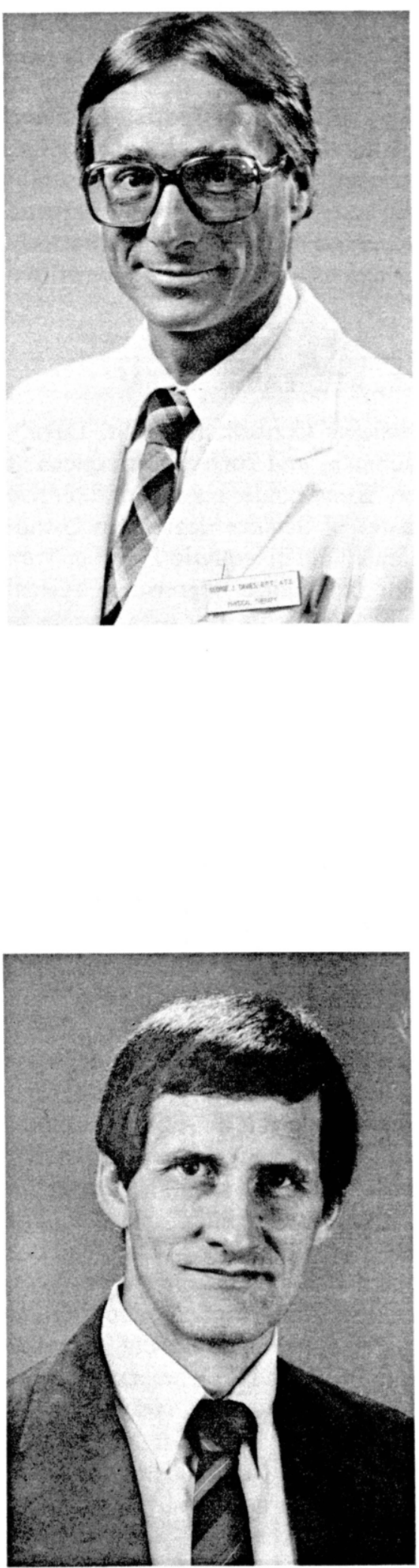

\section{George J. Davies, MEd, PT, ATC}

George J. Davies is an internationally known speaker who has presented conferences throughout the world on sports physical therapy, rehabilitation, and isokinetics. George is a clinician, educator, researcher, speaker, author, editor, and consultant. He has been involved in the clinical practice of sports physical therapy/athletic training for approximately 20 years. George has worked in a variety of settings and with a variety of athletes from children, little leaguers, high school and college athletes in various sports, Olympic athletes, professional karate, nationally ranked athletes, professional football players and teams, and various professional athletes in many sports. George has taught as an educator for 18 years in colleges and universities. He has taught various health and physical education courses, including many graduate level courses, and for the last 15 years has been involved in teaching physical therapy courses including cadaver anatomy, biomechanics, sports physical therapy, orthopaedics, and examination courses.

George has been involved in many research projects that have been presented at many national conferences and published in various journals. $\mathrm{He}$ has also received numerous research grants to further clinically applicable research, particularly in the area of isokinetics. He has participated in hundreds of conferences and workshops all over the world in the last 15 years. He has published over 50 articles in various periodicals as well as has written several books and has contributed chapters to many other books. George had been the co-editor of the Journal of Orthopaedic and Sports Physical Therapy for about nine years, since its inception. He has won many prestigious national awards including Who's Who, Outstanding Young Men of America, and Men of Achievement.

George is presently an Associate Professor of Physical Therapy at the University of Wisconsin-La Crosse Physical Therapy Program. He is also actively involved in clinical practice of sports physical therapy at Orthopaedic and Sports Physical Therapy Clinic, as well as sports coverage of games (approximately 30 football games per year and 100 basketball games).

One of the reasons George has been involved in sports physical therapy is because the former U.S. Marine also likes to think he is an occasional athlete by participating in running (approximately 20 years), marathoning, triathlons, weight training, and the martial arts, where he holds an advanced belt in karate.

\section{Terry R. Malone, EdD, PT, ATC}

Raised an Ohioan, Terry attended Bluffton College and received a baccalaureate degree in 1973. From 1973 to 1975, he attended Duke University where he received a Master of Science and Certificate of Physical Therapy. Ten years later, in 1985, he went on to receive a Doctorate in Education, also at Duke. From 1975 through 1980, Terry coordinated Sports Physical Therapy Services for Orthopaedics at Duke University, after which he left Duke to assume the position of the initial chair of Physical Therapy at the University of Indianapolis. From 1980 through 1986, he held that position and served as an associate professor of what then became the Krannert 
Graduate School of Physical Therapy at the University of Indianapolis. In January of 1987, Terry returned to Duke University as the executive director of Sports Medicine, with appointments of associate professor in Physical Therapy and assistant professor in Surgery. He has been an active member of the Sports Physical Therapy section of the American Physical Therapy Association (APTA), and served as the first chair of the Sports Physical Therapy Specialization Council. He has also served as liaison from the APTA to the National Athletic Trainers Association (NATA) as well as to the American Orthopaedic Society for Sports Medicine (AOSSM). He is an active member of all three organizations (APTA, NATA, and the AOSSM). Terry has numerous publications and presentations dealing with isokinetics and has been actively involved with isokinetic research for more than 15 years. He has served as an editor of a quarterly book series (Sports Injury Management) and as an associate editor of two other journals.

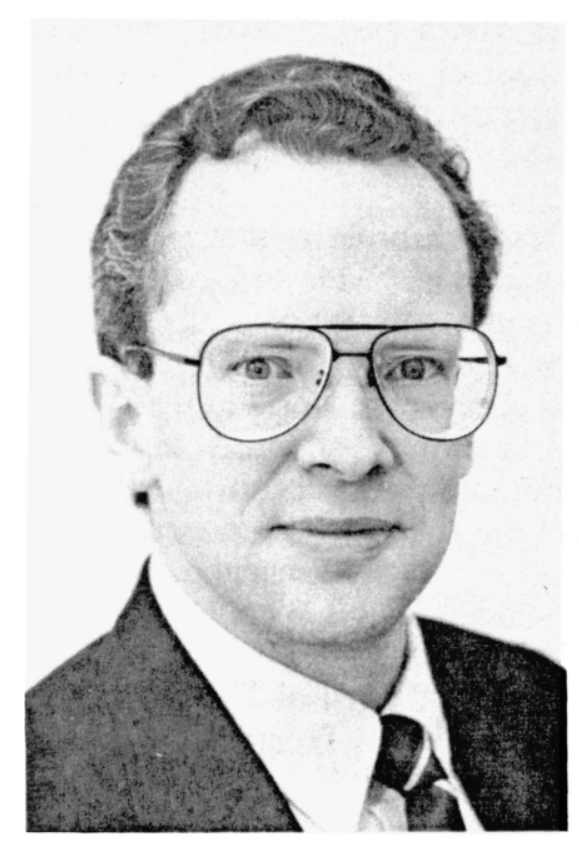

\section{Kent E. Timm, PhD, PT, SCS, OCS, ATC, FABS, FACSM}

Kent Timm is the Sports/Industrial Medicine Consultant for St. Luke's Healthcare Association of Saginaw, Michigan, and currently practices at the St. Luke's Sports Medicine Center. Kent holds a PhD in Exercise Science from Columbia University, Master of Science degrees in Orthopaedic Physical Therapy, in Sports Medicine, and in Athletic Training from the University of Pittsburgh; a Bachelor of Science degree in Physical Therapy from the University of Pittsburgh; and Bachelor of Arts degrees in Biology and Sports Medicine from Ripon College. He is a Fellow of the American College of Sports Medicine and also a Fellow of the American Back Society. Kent holds Board Certifications as an Athletic Trainer through the National Athletic Trainers Association and as a Sports Clinical Specialist and an Orthopaedic Clinical Specialist through the American Board of Physical Therapy Specialties. Professionally, Kent is a member of the Sports Physical Therapy, Orthopaedic, and Research Sections of the American Physical Therapy Association, the Michigan Physical Therapy Association and the MPTA Institute for Education and Research, the Great Lakes Athletic Trainers Association and the Michigan Athletic Trainers Association, the National Strength and Conditioning Association, the Amateur Hockey Association of the United States, the United States Team Handball Federation, and the United States Olympic Society. He is also a member of Phi Beta Kappa and Beta Beta Beta National Honor Societies, Mensa International, Phi Delta Theta National Fraternity, the National Geographic Society, and the Planetary Society. Kent is an Adjunct Instructor-Graduate Faculty Appointment-and teaches a course in Industrial Medicine through the Krannert Graduate School of Physical Therapy at the University of Indianapolis, is a Guest Lecturer and Clinical Instructor for the Physical Therapy Program of the University of Michigan-Flint, and is a Guest Lecturer for Andrews University and Delta College. Kent has been an invited speaker and a consultant in the fields of isokinetic science, sports medicine, industrial medicine, exercise science, and clinical research throughout the United States and in Belgium, Canada, Denmark, France, Germany, Great Britain, Hong Kong, Japan, Mexico, Norway, and the Republic of China. Besides serving as an Associate Editor for The Journal of Orthopaedic and Sports Physical Therapy, Kent has published research and clinical articles in a variety of professional journals, and has written a book entitled Back Injuries and Rehabilitation. Kent has a wife, Debbie, and daughter, Kenzie. 